\title{
EVALUATION OF CONTENT AND LOGICAL VALIDITY OF AFQPHALS SURVEY
}

\author{
Brunilda Subashi ${ }^{1}$ \\ ${ }^{1}$ Scientific Research Center in Public Health, University of Vlora 'Ismail Qemali'
}

October 6, 2020

\begin{abstract}
Introduction: The AFQPHALS Survey (Adult Food Quality and Physical Activity Level Survey), is a semi-structured instrument consisting of 35 questions that evaluate food quality, level of physical activity and provision of health education in adults. Purpose: Evaluation of the content and logical validity of the AFQPHALS survey by a group of experts. Methodology: The evaluation of the content and logical validity of the AFQPHALS survey was conducted on May 17, 2020, by a group of experts, who evaluated the instrument independently. Each expert answered 9 questions in relation to the content and logical of the AFQPHALS survey, on a Likert scale from 1 to 5 . After the evaluation of the content and logical validity of the AFQPHALS survey was performed AFQPHALS pilot test on an adult sample, who also assessed if they had encountered difficulties during the completion of the AFQPHALS survey and if the AFQPHALS survey questions needed further modifications, adjustments or improvements. Results: From the evaluation of experts resulted that, the average points of all the questions of the evaluation instrument of the AFQPHALS survey were 4.81 points (between I agree and completely agree). After AFQPHALS pilot test, in relation to the difficulties encountered during the completion of the survey and the need for further modifications, adjustments or improvements of instrument, resulted with no difficulties during the completion of the survey and with no need for further modifications, adjustments or improvements of instrument. Conclusions: After evaluating the AFQPHALS survey by a group of experts, and after AFQPHALS pilot test and evaluation of difficulty and need to improvements of the instrument by an adult sample, the AFQPHALS survey proved to be suitable for use in the population.
\end{abstract}

Keywords: AFQPHALS survey, content validity, logical validity, experts.

\section{Introduction}

\section{AFQPHALS survey}

The AFQPHALS Survey (Adult Food Quality and Physical Activity Level Survey), is a semi-structured instrument consisting of 35 questions that evaluate food quality, level of physical activity and provision of health education in adults.

\section{Origin of the AFQPHALS survey}

The AFQPHALS instrument (consisting of 35 questions), originates from the ECAAM instrument (Encuesta de Calidad de Alimentación del Adulto Mayor), which means Food Quality Survey of Elderly (FQSE), an valid structured instrument and applied to the elderly, consisting of 23 questions.

\section{Evolution of the investigation instrument}

The FQSE survey was translated, adapted into Albanian and question 14 and the response alternatives of questions $8,13,14$, and 19 were adapted and the score was eliminated.

On May 17, 2020, after consulting with the author of the FQSE survey, Samuel Durán Agüero about the use of this instrument in adults and the approval of his permission for the use of this instrument in Albania, I added to the FQSE instrument some other questions, such as: the level of physical activity and some sociodemographic data, and 3 optional questions, which would be necessary to fulfill the purpose of this study, 
creating the new semi-structured instrument, the AFQPHALS Survey (Adult Food Quality and Physical Activity Level Survey).

AFQPHALS was incorporated into the e-encuesta.com platform in the form of an online questionnaire.

Subsequently, the AFQPHALS survey was subject to evaluation of the content and logical validity by a group of experts, the AFQPHALS pilot test and the evaluation to detect if it presented difficulties during the completion of the survey by the participants of the pilot test, as well such as the need for instrument modifications, adjustments or improvements.

\section{Content of the AFQPHALS survey}

* Questions 1 to 23 that assess the quality of food were adapted from the FQSE survey (Duran Aguero, Candia and Pizarro Mena, 2017)

* Question 24 to assess the level of physical activity was formulated according to the literature. (Spanish Nutrition Foundation (FEN))

* Questions 25-32 are questions about universal / socio-demographic data,

* Questions 33, 34 and 35 are optional questions, for subjects who want to benefit from health education, who accompanied the survey.

Question 33 was added for subjects who want to receive health education with personalized information on body parameters, as well as advice on healthy eating and physical activity with respect to the AFQPHALS survey questions.

Question 34 was added to enter the email address of the person interested in health education with the services mentioned above.

Question 35 was added to refer to problems or diseases, with the aim of dietary advice for each of them based on their health problems or diseases.

Presentation of AFQPHALS survey

AFQPHALS SURVEY (Adult Food Quality and Physical Ac 


\section{Evaluation of the content and logical validity of the AFQPHALS survey by a group of experts}

The evaluation of the content and logical validity of the AFQPHALS survey was conducted on May 17, 2020, by a group of experts ( 15 health professionals with experience in clinical and research fields, as well as experts from the Scientific Research Center in Public Health, Faculty of Public Health, University 'Ismail Qemali' of Vlora), who evaluated the instrument independently. Each expert answered a structured questionnaire of 9 questions in relation to the content and logical validity of the AFQPHALS survey, on a Likert scale from 1 to 5 ( 1 = disagree, $2=\mathrm{I}$ don't agree, $3=\mathrm{I}$ 'm not sure, $4=\mathrm{I}$ agree, $5=$ completely agree).

\begin{tabular}{|c|c|c|c|c|c|c|}
\hline No. & $\begin{array}{l}\text { Questions } \\
\text { for } \\
\text { evaluating } \\
\text { the } \\
\text { AFQPHALS } \\
\text { instrument }\end{array}$ & 1 & 2 & 3 & 4 & 5 \\
\hline 1 & $\begin{array}{l}\text { The questions } \\
\text { are simple and } \\
\text { clear in } \\
\text { formulation. }\end{array}$ & - & - & - & 1 & 14 \\
\hline 2 & $\begin{array}{l}\text { With these } \\
\text { questions, can } \\
\text { be assessed } \\
\text { aspects of food } \\
\text { quality and } \\
\text { level of } \\
\text { physical } \\
\text { activity. }\end{array}$ & - & - & - & 4 & 11 \\
\hline 3 & $\begin{array}{l}\text { Ranking } \\
\text { questions } \\
\text { facilitates } \\
\text { information on } \\
\text { food quality } \\
\text { and level of } \\
\text { physical } \\
\text { activity. }\end{array}$ & - & - & - & 3 & 12 \\
\hline 4 & $\begin{array}{l}\text { The answer } \\
\text { alternatives } \\
\text { are simple and } \\
\text { clear on } \\
\text { formulation. }\end{array}$ & - & - & - & 1 & 14 \\
\hline 5 & $\begin{array}{l}\text { The answers } \\
\text { to the } \\
\text { questions are } \\
\text { appropriate. }\end{array}$ & - & - & - & 2 & 13 \\
\hline
\end{tabular}




\begin{tabular}{|c|c|c|c|c|c|c|}
\hline No. & $\begin{array}{l}\text { Questions } \\
\text { for } \\
\text { evaluating } \\
\text { the } \\
\text { AFQPHALS } \\
\text { instrument }\end{array}$ & 1 & 2 & 3 & 4 & 5 \\
\hline 6 & $\begin{array}{l}\text { The } \\
\text { instrument is } \\
\text { suitable to be } \\
\text { administered } \\
\text { au- } \\
\text { tonomously/ } \\
\text { independently } \\
\text { by an adult. }\end{array}$ & - & - & - & 3 & 12 \\
\hline 7 & $\begin{array}{l}\text { This } \\
\text { instrument can } \\
\text { identify the } \\
\text { quality of food } \\
\text { and the level } \\
\text { of physical } \\
\text { activity of a } \\
\text { single } \\
\text { individual or } \\
\text { population. }\end{array}$ & - & - & 2 & 1 & 12 \\
\hline 8 & $\begin{array}{l}\text { This } \\
\text { instrument has } \\
\text { been adapted } \\
\text { from the } \\
\text { original } \\
\text { instrument } \\
\text { (ECAAM/ } \\
\text { FQSE) to } \\
\text { assess the } \\
\text { quality of food } \\
\text { in adults and } \\
\text { has been } \\
\text { modified to } \\
\text { assess the level } \\
\text { of physical } \\
\text { activity in } \\
\text { adults. }\end{array}$ & - & - & - & 3 & 12 \\
\hline
\end{tabular}




\begin{tabular}{|c|c|c|c|c|c|c|}
\hline No. & $\begin{array}{l}\text { Questions } \\
\text { for } \\
\text { evaluating } \\
\text { the } \\
\text { AFQPHALS } \\
\text { instrument }\end{array}$ & 1 & 2 & 3 & 4 & 5 \\
\hline 9 & $\begin{array}{l}\text { Would you } \\
\text { recommend } \\
\text { this } \\
\text { instrument to } \\
\text { assess the } \\
\text { quality of food } \\
\text { and the level } \\
\text { of physical } \\
\text { activity in a } \\
\text { single } \\
\text { individual or } \\
\text { in a } \\
\text { population. }\end{array}$ & - & - & - & 3 & 12 \\
\hline
\end{tabular}

\begin{tabular}{lllllll}
\hline Question & Total participants & Sum & Average & Standard deviation & Minimum & Maximum \\
\hline Q1 & 15 & 74.00 & 4.93 & 0.25 & 4.00 & 5.00 \\
Q2 & 15 & 71.00 & 4.73 & 0.44 & 4.00 & 5.00 \\
Q3 & 15 & 72.00 & 4.80 & 0.40 & 4.00 & 5.00 \\
Q4 & 15 & 74.00 & 4.93 & 0.25 & 4.00 & 5.00 \\
Q5 & 15 & 73.00 & 4.87 & 0.34 & 4.00 & 5.00 \\
Q6 & 15 & 72.00 & 4.80 & 0.40 & 4.00 & 5.00 \\
Q7 & 15 & 70.00 & 4.67 & 0.70 & 3.00 & 5.00 \\
Q8 & 15 & 72.00 & 4.80 & 0.40 & 4.00 & 5.00 \\
Q9 & 15 & 72.00 & 4.80 & 0.40 & 4.00 & 5.00 \\
\hline
\end{tabular}

\section{[CHART]}

From the evaluation of experts resulted that, average total points for each question of the AFQPHALS survey assessment instrument, it was:

Q1- The questions are simple and clear in formulation (4.93);

Q2- With these questions, can be assessed aspects of food quality and level of physical activity (4.73);

Q3- Ranking questions facilitates information on food quality and level of physical activity (4.80);

Q4- The answer alternatives are simple and clear on formulation (4.93);

Q5- The answers to the questions are appropriate (4.87);

Q6- The instrument is suitable to be administered autonomously/ independently by an adult (4.80);

Q7- This instrument can identify the quality of food and the level of physical activity of a single individual or population (4.67); 
Q8- This instrument has been adapted from the original instrument (ECAAM/FQSE ) to assess the quality of food in adults and has been modified to assess the level of physical activity in adults (4.80);

Q9- Would you recommend this instrument to assess the quality of food and the level of physical activity in a single individual or in a population (4.80).

Average points of all questions of the AFQPHALS survey assessment instrument resulted 4.81 points $(4=$ I agree, $5=$ completely agree).

AFQPHALS pilot test and assessment of the difficulty and the need for improvements of the instrument.

On May 17, 2020, AFQPHALS pilot test was performed on an adult sample of 30 subjects, who also completed a semi-structured questionnaire with 4 questions for evaluation if they had encountered difficulties during the completion of the AFQPHALS survey and if the AFQPHALS survey questions needed further modifications, adjustments or improvements.

Q1. Is there any difficulty to complete the AFQPHALS survey? [CHART]

Q3. Do you think the AFQPHALS survey needs further modifications, adjustments or improvements? [CH

In relation to the difficulties encountered during the completion of the survey and the need for further modifications, adjustments or improvements, resulted with no difficulties during the completion of the AFQPHALS survey (100\%) and with no need for further modifications, adjustments or improvements (100\%).

\section{Conclusions}

- The AFQPHALS survey is a very easy tool for researchers to use, and is a simple and easy tool to apply in adults.

- The questions are simple and clear in formulation and allows evaluating and characterizing the quality of the diet according to the respective food groups and the level of physical activity of adults.

- The instrument is suitable to be administered autonomously/ independently by an adult.

- This instrument can identify the quality of food and the level of physical activity of a single individual or population.

- The AFQPHALS survey resulted with no difficulties during the completion and with no need for further modifications, adjustments or improvements.

- After evaluating the AFQPHALS survey by a group of experts, and after pilot test and evaluation of difficulty and need to improvements of the instrument by an adult sample, the AFQPHALS survey proved to be suitable for use in the population.

\section{References}

